\title{
ON THE FUNCTIONS AND MORPHOLOGY OF THE POSTCLAVICULAR APPARATUS IN SPHEROIDES AND CHILOMYCTERUS
}

\section{By Albert Eide ParR}

The Bingham Oceanographic Collection ${ }^{1}$

(Figs. 285-293 incl.)

\section{INTRODUCTION}

While observing the movements of some specimens of Spheroides maculatus (Bloch and Schneider) in the tanks of the New York Aquarium the author noticed some very peculiar actions taking place when the fishes descended to rest upon the bottom, usually while they were still a few inches above it. When the fishes were swimming freely in the water their body was seen to be of a fusiform shape, practically circular in transverse section through the region of the belly, with the greatest width between the bases of the pectoral fins. When, on the other hand, the fishes approached the bottom a peculiar change of the outline was observed in dorsal view. The posterior part of the belly was suddenly expanded, becoming laterally produced into rounded angles, thus giving the entire outline of the trunk a somewhat rectangular shape in dorsal view. This change in shape may be more easily understood from an inspection of Fig. 285, where the expanded state is indicated by the broken outline. In

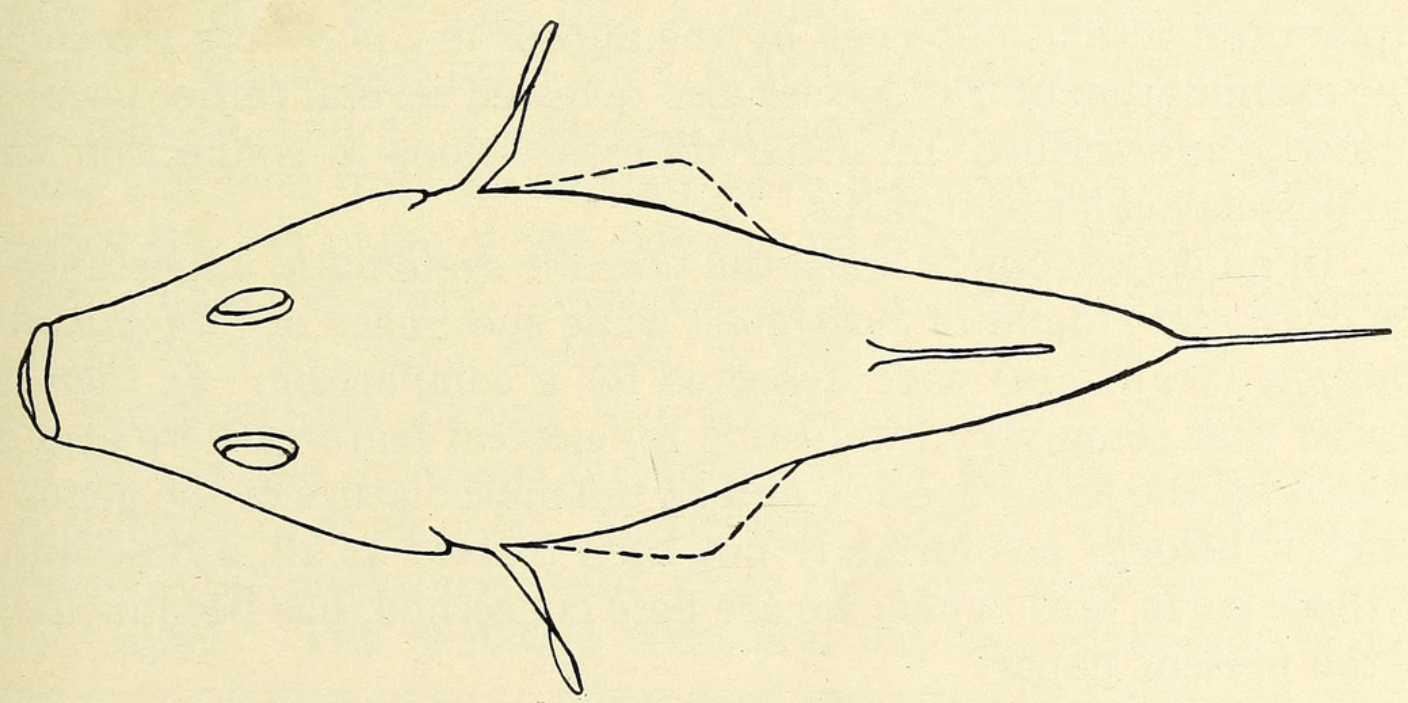

Fig. 285. Dorsal view of Spheroides maculatus. Dashed outline indicates the appearance of the fish when the postclavicles are spread.

${ }^{1}$ Formerly of the New York Aquarium. 
this state the ventral surface of the belly is flattened and the greatest width may usually be measured between the posterior corners of the expanded belly.

An anatomical examination of the fishes shows that these corners correspond to the posterior ends of the very large second (inferior) postclavicular bones on each side, the expansion of the belly being brought about by a spreading of the postclavicular apparatus. To the best of the author's knowledge this is the only case in which the postclavicles have been observed to function as independent units with direct external effect. For this reason a closer examination and description seems justified.

In the literature dealing with the anatomy of the Tetrodontidae very little has been said about the finer details of the musculature. Thilo (1899) loosely mentions that in Tetrodon "two broad muscles originate from the postclavicles, the anterior of which inserts itself into the lower end of the pectoral arch, the posterior one at the carrier of the anal fin." 2 Rosen (1913) gives a much more thorough description of the body muscles of Spheroides testudineus (Linnaeus). Concerning the postclavicular apparatus however he only mentions that "the anterior part of the m. obliquus inferior is attached to the postclavicle," and further that "a small lateral portion (of the rectus) is distinct and is inserted into the free tip of the postclavicle."

The muscular arrangements thus very briefly described by former investigators of the Tetrodontidae seemed insufficient to explain the actions observed by the author in Spheroides maculatus. The examination of this species also revealed several rather peculiar, formerly undescribed, muscular differentiations in connection with the postclavicular apparatus.

In an endeavour to trace the possible systematic importance of the characters found in Spheroides some specimens of Chilomycterus schoepfii (Walbaum) were dissected for a comparison. It then appeared that some very interesting myological features were also exhibited by the latter species, and as the musculature of the genus to which it belongs has formerly not been treated at all, a description of those parts, with which we are here concerned, has been included in the present paper.

${ }^{2}$ Freely translated from the german text (Die Entst. d. Lufts. b. d. Kugelfischen. Anat. Anz. 1899.) 


\section{SYSTEM OF TERMINOLOGY}

Before beginning the description it is necessary to adopt a definite system of terminology for the muscles in question. The author agrees with Rosen (1913) in the view that a terminology based upon the probable phylogenetic homology of the muscles is highly desirable, and would serve to clear the present confusion of purely descriptive names. It would however on the other hand alone be quite insufficient for practical use, because the muscular elements, which are generally recognizable as homologous through all groups of fishes, are so very few and so very broadly defined, as compared with the great number of specialised muscles developed in many smaller groups through differentiation and separation of parts only of the primary elements.

These specialised muscles, when they are developed, generally will be found to be of a considerably greater functional importance to the individual than the primary elements as such, and a purely phylogenetic terminology will necessarily result in more or less vague names for such specialised muscles, or more correctly will give no names to them at all, merely describing them as "the part of the musculus so and so functioning (or inserted) so and so." Such terminology will therefore be just as unsatisfactory to the student of animal behaviour as a purely descriptive one is to the comparative morphologist. To meet the just demands from both sides the author therefore proposes that a double terminology be adopted, giving the specialised parts their definite names according to their specialisation, and at the same time ascribing them to the phylogenetic elements from which they have been developed. Thus for instance the full name of the extensor postclavicularis described on p. 255 stands: extensor postclavicularis musculi obliqui inferioris spheroidi. ${ }^{3}$ This name certainly is rather long, but still will be more practical than having to mention the muscle in question as "the part of the musculus obliquus inferior serving to extend the post-clavicles in Spheroides" and so forth, and will also prevent any confusion that might arise from using the name extensor postclavicularis alone. The proposed term also has the advantage of not being a description open to misunderstandings, but a name to which a definite diagnosis may be given once and for all. It will therefore

- Or for instance: pars coraco-analis musculi recti spheroidi, see p. 250. 
represent to the reader a descriptively and as far as possible, also, phylogenetically well defined muscle. In comparative treatises the name of the species, genus, family or group in which the special muscle under discussion has been recognised and to which the author refers, always ought to be added to the name of the muscle to definitely establish the identity. If the proposed system of terminology is adopted it is of course not necessary always to mention the long names unabbreviated. When dealing exclusively with a special group or species of fishes or with the differentiations of a special primary element of the musculature the corresponding parts of the name may certainly for practical purposes be omitted by its repeated use in the text.

The names applied to the primary elements of the musculature are all adopted from the terminology introduced by Maurer (1899).

The Postclavicular Apparatus of Spheroides Maculatus

Osteological Apparatus

The posttemporals are ancylosed with the epiotics. The supraclavicles are thus directly suspended from the skull. They run obliquely backwards to the upper part of the cleithrum.

Contrary to the general rule the two post-clavicles are firmly attached to each other, the slender upper end of the second (inferior) bone fitting into a groove in the first (superior) one. The connection between the postclavicular apparatus and the cleithrum also is of a very peculiar nature, the superior postclavicle forming a sliding, saddle-like articulation with the convex interior surface of the upper part of the cleithrum as may be understood from Fig. 286. A third

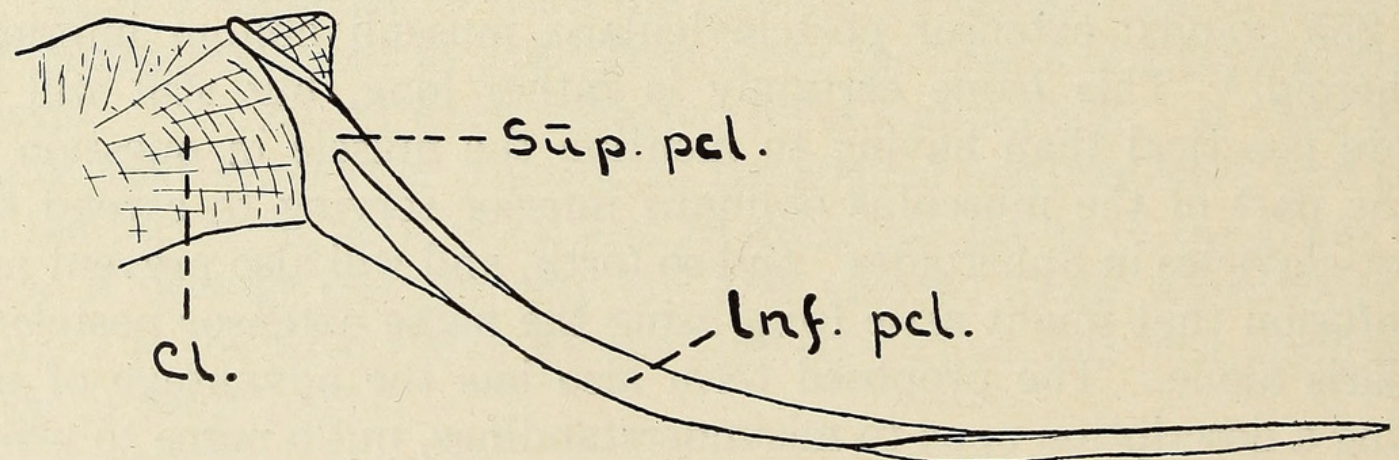

Fig. 286. Ventral view of the right postclavicular bones and the upper part of the cleithrum of Spheroides maculatus; Cl, cleithrum; Inf.pcl, inferior postclavicle; Sup.pcl, superior postclavicle. 
peculiar feature of the postclavicular apparatus of these fishes is contributed by the fact that the inferior postclavicular bone is several times as large as the superior one. The superior bone is short and strong, broader than high. The articulating surface (for the cleithrum) occupies nearly half its entire length. The upper part of the inferior postclavicular bone is long and slender, fitting into the groove of the superior bone. The lower part is thin and compressed (broadened vertically), of a lanceolate outline in lateral view. An inspection of the Figs. 286 and 287 will show these relations

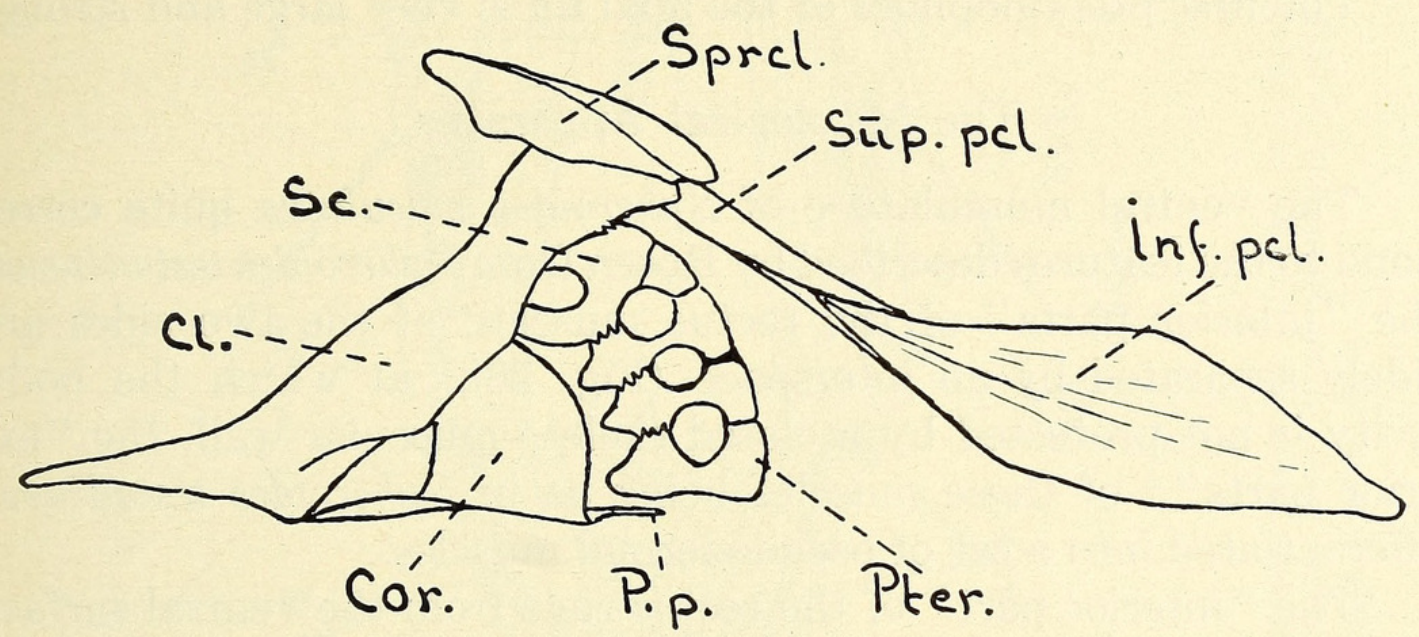

Fig. 287. Lateral view of the left pectoral arch and postclavicles of Spheroides maculatus; $\mathrm{Cl}$, cleithrum; Cor, coracoid; Inf.pcl, inferior postclavicle; P.p. posterior process of the ventral lamina on the coracoid; Pter, pterygials; Sc, scapula; Sprcl, supraclavicular bone; Sup.pcl, superior postclavicle.

better than a description can do. The total length of the postclavicular apparatus measured from the upper anterior end of the superior bone to the posterior end of the inferior bone equals about half of the entire distance between gill openings and anal fin. The free part of the apparatus i.e. the part not covered by the cleithrum equals about two-fifths of the same distance.

The cleithrums run obliquely downwards and forwards, connecting through cartilage and connective tissue below the throat.

The scapula is rather reduced and united with the likewise reduced first pterygial. The other three pterygials are all connected with the coracoid. The lower pterygial has a more or less well developed, small, mesial, horizontal lamina from the ventral margin. This lamina in some individuals may be produced into a feeble spinelike process, opposed to the posterior process from the lamina of the coracoid. 
The posterior part of the coracoid is vertical and rounded with a well developed mesial horizontal lamina from its lower margin. From its posterior mesial corner the lamina forms a backwardly directed spinelike process serving to strengthen and enlarge the margin of insertion for the extensor postclavicularis musc. obl. inf. described on p. 255. Anteriorly the vertical part of the coracoid disappears, leaving a great foramen between the coracoid and the cleithrum, while the horizontal lamina is widened and considerably strengthened.

The first pterygiophore of the anal fin is very large and strong.

\section{The Myological Apparatus}

The ventral musculature of Spheroides maculatus quite correspond to the features described by Rosen from Spheroides testudineus. The "interior parts" of the rectus muscles ${ }^{4}$ of the two sides are widely separated by an interspace (Fig. 288) at which the body cavity is not protected by a closed skeleto-muscular wall, the "exterior parts" "of these muscles being as in Spheroides testudineus differentiated into a set of pseudodermal muscles.

The "interior part" of the rectus runs from the ventral surface of the anterior, horizontal part of the coracoid backwards to the first pterygiophore of the anal fin, and may therefore be called: pars coraco-analis musculi recti. ${ }^{5}$ The coraco-analis is distinctly but somewhat irregularly segmented. At the third septum the connective tissue sheath of the coraco-analis unites above with the ligament (the facia transversa of Thilo) which is further up attached to the interior surface of the postclavicular bones.

The retractor postclavicularis musculi recti is a slender but very well defined muscle running closely along the posterior part of the coraco-analis, partly even imbedded in the latter, still very distinct however by its somewhat yellowish color and its complete lack of segmentation. This muscle has already been mentioned by Rosen as a "small lateral portion" of the rectus (see quotation p. 246). It originates together with the coracoanalis from the first pterygiophore of the anal fin and is anteriorly inserted into the posterior free

1 See Rosen (1913).

5 The descriptive term, protractor analis, used by several authors for analogous and probably more or less homologous structures, is rather unsatisfactory as it will change its meaning according to the presence or absence of a pelvis, covering in the latter case the entire part of the rectus anterior to the anal fin, in the former case however only the part between the anal fin and the pelvis. 


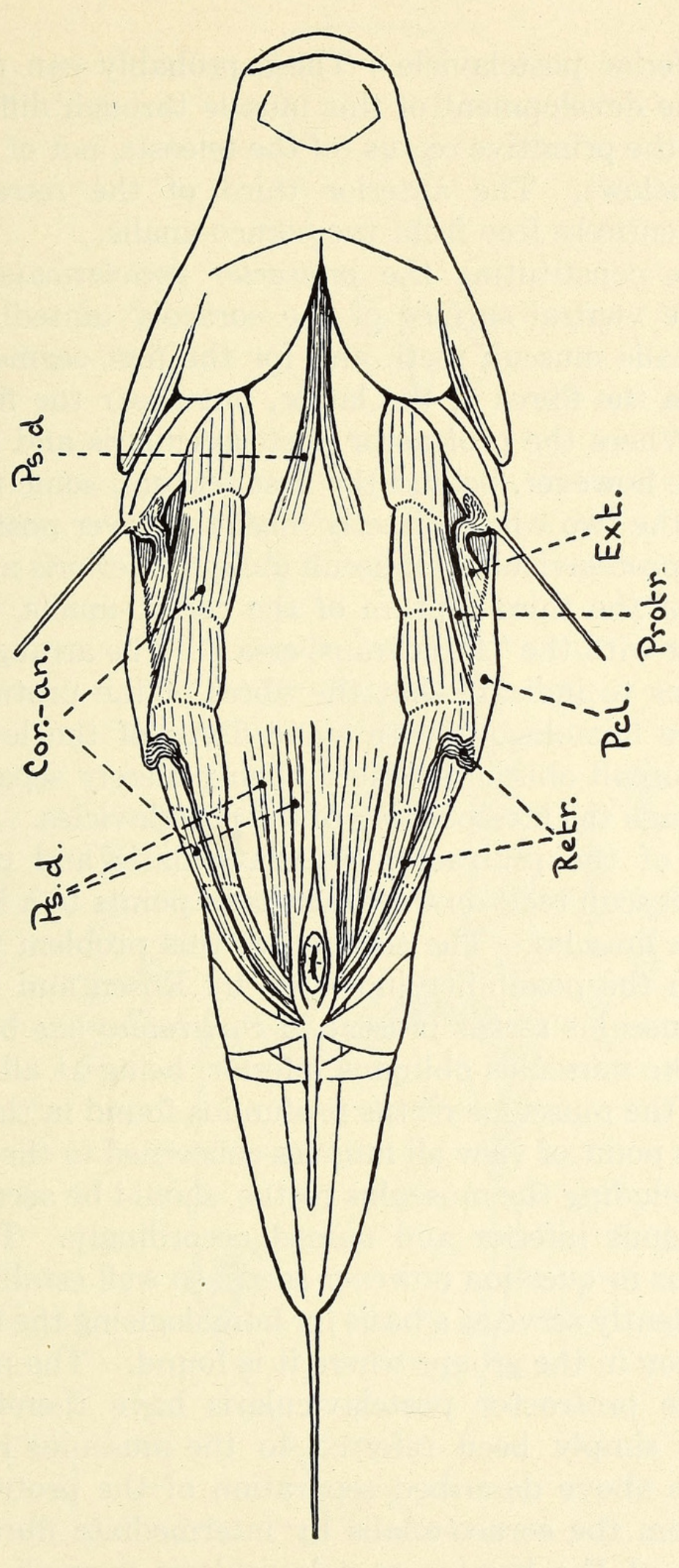

吕:

苟:

: 글

घ

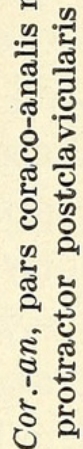

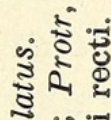

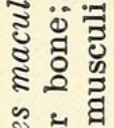

:

究资

4

可 员

䒠

䓀

䎡.

밀

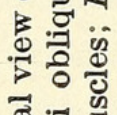

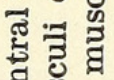

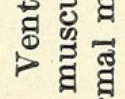

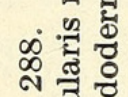

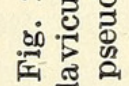

$\begin{array}{ll}\frac{\pi}{0} & 0 \\ 4 & 0 \\ 0 & 0 \\ 0 & 0\end{array}$ 
end of the inferior postclavicle. There probably can not be any doubt as to the development of this muscle through differentiation from a part of the primitive rectus (of the teleosts, not of the sharks, see remarks below). The anterior third of the retractor postclavicularis is entirely free from the coraco-analis.

The fibres constituting the protractor postclavicularis are inserted into the ventral surface of the coracoid unitedly with the pars coraco-analis musculi recti, and for the first segment are not separated from the fibres of the latter, but shear the first septum with these. Where the protractor postclavicularis and the coracoanalis separate however, behind the first septum, some fibres originate between the two which directly meet the lower posterior fibres of the levator postclavicularis musculi obliqui inferioris at the upper continuation of the third septum of the coraco-analis, which connects the latter with the "facia transversa." The arrangement just described seems to indicate that the fibres of the protractor postclavicularis are homologous with some fibres of the levator postclavicularis musculi obliqui inferioris, being merely separated from the latter through the interposition of the postclavicles. The united first segment of the protractor postclavicularis and of the pars coracoanalis musculi recti on the other hand points to a homologous origin of these muscles. The solution of this problem probably is to be found in the possibility indicated by Rosen and others that the type of musculus rectus present in Spheroides has been formed by a part of the musculus obliquus inferior, being at all events not identical with the musculus rectus profundus found in the sharks.

From this point of view all muscles concerned in the present investigation, including the musculus rectus, should be ascribed to the musculus obliquus inferior and named accordingly. The type of musculus rectus in question however seems so well established, that it may conveniently serve as a basis for homologizing the finer details of differentiation in the groups where it is found. The pars coracoanalis and the protractor postclavicularis have therefore in the present paper simply been referred to the musculus rectus. On account of the above described separation of the protractor postclavicularis from the coraco-analis by intermediate fibres, directly meeting fibres of the levator postclavicularis musculi obliqui inferioris, the first mentioned muscle is, on the other hand, directly referred to the $\mathrm{m}$. obliquus inf. as the protractor postclavicularis musculi obliqui inferioris. 


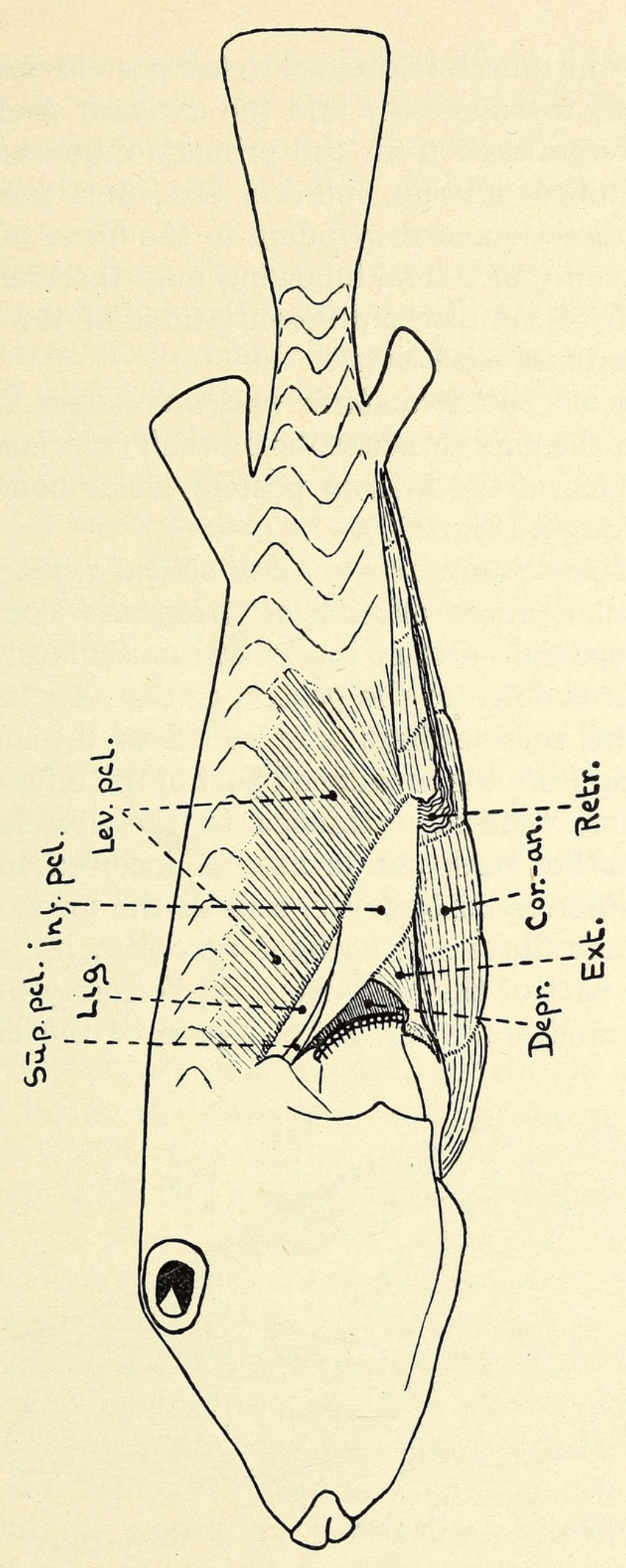

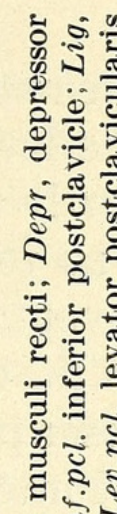

토응

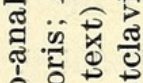

造 造

을

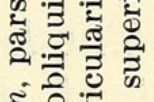

โิ

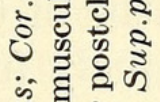

ฐ

ปู

․ㅠㅇㅠ

के 젱

ธิ क्ष

₹

की

范

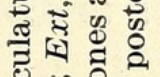

울

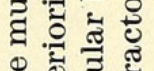

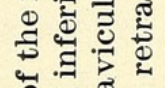

范要

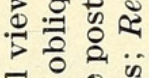

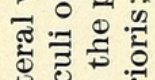

苂总

के

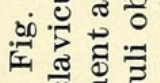

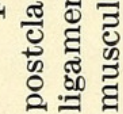


The rest of the muscles attached to the postclavicular apparatus viz.: the levator, the depressor and the extensor probably are also all directly differentiated from the primary musculus obliquus inferior, as their fibres all run, more or less, in a postero-dorsal to antero-ventral direction corresponding to the fibres of the primitive type of $\mathrm{m}$. obl. inferior. The following may therefore be regarded as a description of the direct differentiations of the said muscular element in Spheroides maculatus.

The protractor postclavicularis musculi obliqui inferioris after separating from the pars coracoanalis musculi recti inserts itself into the mesial surface of the inferior postclavicular bone along its anterior ventral margin (Fig. 290).

The levator postclavicularis musculi obliqui inferioris is a broad sheet of muscular fibres originating from the connective tissue sheaths of the epaxial parts of the lateral musculature and running obliquely forwards down to the postclavicular apparatus. The anterior part of this muscle-sheet is attached to the mesial side of a ligament running from the broadened part of the inferior postclavicle to the cleithrum, ventrally attached to the postclavicular bones (Fig. 289). Farther back the levator is inserted into the dorsal margin of the inferior postclavicle, and at the lower posterior part of this bone some fibres run straight across to its ventral margin separating this part of the bone from the formerly mentioned ligament or facia transversa (Fig. 290). Some of the lower posterior

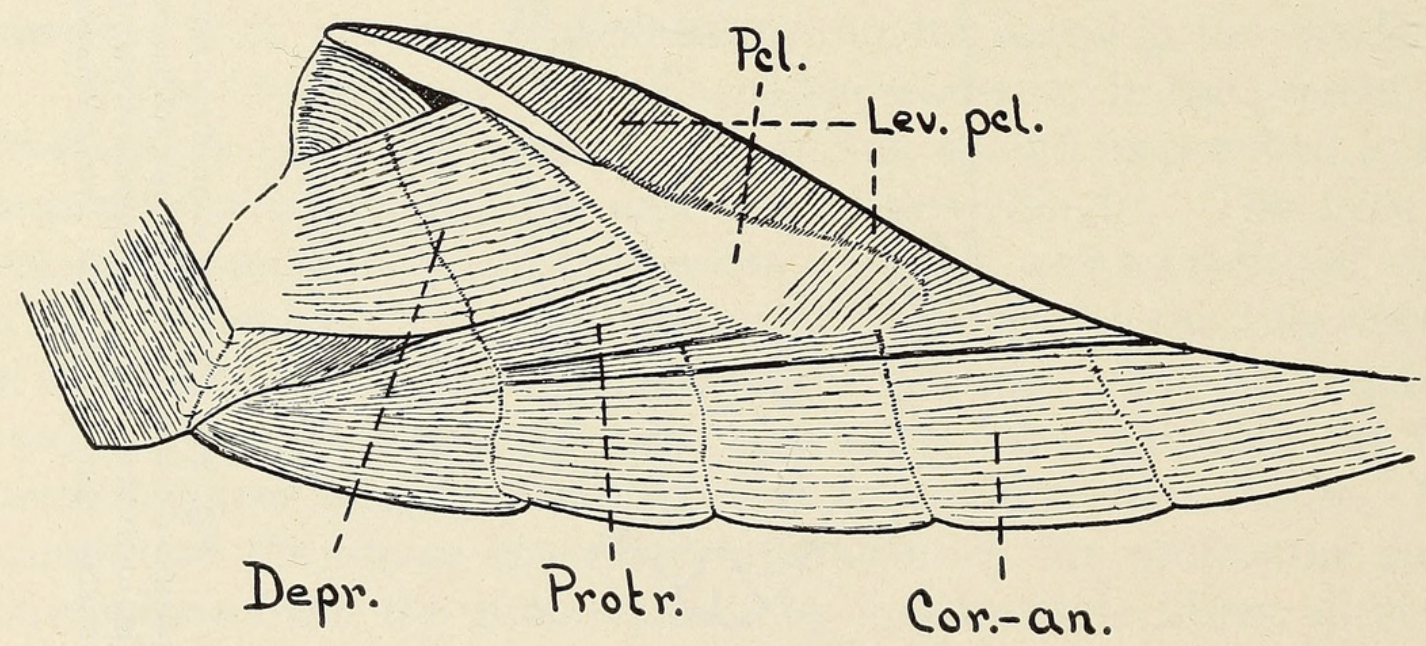

Fig. 290. Interior view of the muscular wall of the body-cavity in Spheroides maculatus Cor.-an, pars coraco-analis musculi recti; Depr, depressor postclavicularis musculi obliqui inferioris: Lev.pcl, levator postclavicularis musculi obliqui inferioris: $P c l$, postclavicular bone; Protr, protractor postclavicularis musculi obliqui inferioris. 
fibres of the levator, meeting the intermediate fibres between the protractor postclavicularis and the coraco-analis, are more or less horizontal and posteriorly ending in the connective tissue between the lateral musculature and the skin without any definite attachment.

As will appear from the above descriptions and the Figs. 289 and 290 the exact boundaries between the protractor-levator postclavicularis system of the musculus obliquus inferior and the pars coraco-analis of the musculus rectus are nowhere distinct, being more or less effaced by united segments or intermediate fibres. This fact strongly supports the theory that the rectus of the type present in these fishes has been developed from a part of the original musculus obliquus inferior, but does not, however, essentially effect the individual independency of the muscles described.

A most prominent and peculiar feature of the postclavicular apparatus is the well separated and sharply limited extensor postclavicularis musculi obliqui inferioris which runs from the antero-ventral margin of the inferior postclavicle forwards to the pectoral arch where it is inserted into the posterior margin of the horizontal lamina of the coracoid, strengthened and enlarged by the posterior process, and into the small lamina of the lower pterygial.

\section{The Functions}

The spreading of the postclavicles evidently is brought about by the contraction of the extensor postclavicularis musculi obliqui inferioris, this being the only muscle connected with the postclavicular bones which has its other end inserted at an external antero-lateral angle with the axis of the skeletonous postclavicular apparatus.

The effect of a contraction of the retractor postclavicularis musculi recti is evident, but the use the living fishes make of it is not so clear. In the specimens dissected after they had been killed and fixed in formaldehyde the pars coraco-analis musculi recti was contracted and the postclavicles were gathered close to the sides. In this state the retractor postclavicularis is however not contracted, as should be expected, to keep the postclavicles back and to the side; but is on the contrary quite relaxed, even being folded, and is evidently quite without function under these circumstances. The same also holds good of the extensor and levator postclavicularis 
musculi obliqui inferioris. There thus seems to be two different sets of muscles controlling the actions and positions of the postclavicular apparatus, one set consisting of the extensor and the levator postclavicularis musculi obliqui inferioris together with the retractor postclavicularis musculi recti for spreading and operating the apparatus in its active state, another set mainly consisting of the pars coraco-analis musculi recti for gathering the apparatus to the side and fixing its position in its passive state. The depressor and the protractor postclavicularis musculi obliqui inferioris possibly partake of the functions of both sets as they are both found in a state of slight tension in the fixed specimens above described, with the postclavicles in the passive state, while the movements observed in the active state also indicate the possibility of an active depression of the postclavicles during the "squirming" to be described later. These relations will be more easily understood after they have been treated in detail below.

It is convenient for an adequate understanding first to describe the effect of the pars coraco-analis musculi recti. As will appear very clearly from Fig. 288. (showing these muscles in tension already) a contraction of the muscles in question will cause their middle parts to move towards the median plane of the fish. Through the upward connection of the third septum of the $\mathrm{p}$. coraco-analis $\mathrm{m}$. recti with the ligament attached to the postclavicles the latter are forced to join the said muscle in its approach towards the median plane, and will thus be gathered to the side and kept firmly in this position as long as the $\mathrm{p}$. coraco-analis $\mathrm{m}$. recti stays contracted. In the just described state a contraction of the retractor postclavicularis $\mathrm{m}$. recti is therefore entirely unneccessary and we thus understand why this muscle seems not to function under such conditions. At the same time it also becomes evident that the tension of the contracted pars coraco-analis $\mathrm{m}$. recti will prevent the spreading or any movement at all of the postclavicles, we therefore must assume that the active operations of the postclavicular apparatus are preceded by the relaxation of the pars coraco-analis $m$. recti, after which the above mentioned muscle-set of the active state comes into play.

The function of the retractor postclavicularis musculi recti then will be to act as an antagonistic muscle to the extensor postclavicularis $\mathrm{m}$. obl. inf. thus establishing a control of the operations and positions of the postclavicles in the active state which would other- 
wise not have been possible with the pars coraco-analis $\mathrm{m}$. recti out of function. It probably also serves to retract the postclavicles during the squirming, if such retraction takes place at all (see p. 259).

As already mentioned the levator postclavicularis musculi obliqui inferioris also seems out of function (i. e. not even in tonus) when the postclavicles are gathered to the side. When they are spread a contraction of the levator in addition to lifting the apparatus, will also serve to give it an "upward" twist, drawing its dorsal margin towards the median in counteraction with the extensor postclavicularis m. obl. inf. pulling the ventral margin outwards. Thus the levator and the extensor postclavicularis m. obl. inf. between them will be able to produce a perfect shoveling operation of the postclavicular apparatus.

The depressor and the protractor postclavicularis m. obl. inf. both will pull the apparatus forwards and downwards, at the same time on occasion twisting its lateral surface back to the vertical plane. The tension of the depressor probably also serves to keep the postclavicular apparatus in a downwards direction, when the latter is used for support of the resting fish.

We now have an explanation of how the operations of the postclavicular apparatus may be supposed to be effected by the muscles attached to it. The postclavicles are gathered close to the sides and kept in that position, in which they are observed in the freely swimming fish, mainly by contraction of the pars coraco-analis musculi recti which is indirectly connected with the lower part of the apparatus. In this state the extensor, the levator and the retractor postclavicularis are relaxed. To be moved and extended the postclavicular apparatus must first be relieved by a relaxation of the pars coraco-analis m. recti, after which the spreading is effected and controlled by the interaction of the extensor and the retractor postclavicularis. Through the levator postclavicularis the extended apparatus may be given a shoveling twist and movement upwards, and may then be twisted and pulled down again by the protractor and the depressor postclavicularis. The latter muscle, perhaps also the protractor postclavicularis, finally keeps the postclavicles in position when these are serving for support of the body upon the ground.

\section{The Significance Of The Postclavicular Apparatus}

As formerly described, the fishes will spread their postclavicular apparatus just before descending to the bottom to rest upon it. 
Since the fishes considered have no ventral fins at all and the position and structure of the pectorals is such that these fins are of no value as a support to the resting fish (as may easily be observed in an aquarium), the spreading of the postclavicles may in such cases simply serve to produce a broader basis to rest upon, attained in other fishes by the support from the ventral and pectoral fins. According to Mr. L. L. Mowbray, Director of the Bermuda Aquarium, these fishes generally prefer muddy bottoms to the harder ones, and under such conditions the flattening and enlargement of the ventral surface, stretched between the extended postclavicles, may very well serve to prevent the fishes from sinking too quickly or to deeply into the soft mud. In fishes resting upon the bottom the postclavicular apparatus is not twisted but on the contrary has its lateral surface in the vertical plane.

The very much enlarged postclavicles of Spheroides functionally more or less replace the ribs, which are completely lacking in these fishes; as already mentioned by Thilo (1899) in reference to Triacanthus. By the absence of ribs and a strong, closed, ventral, muscular body wall it may become important that the weight of the body is kept from pressing upon the body-cavity, thus interfering with the functions of the internal organs. The rather strong musculature for downwardly directing the postclavicular apparatus may therefore probably serve to keep the resting body lifted on the points of the postclavicles, thus relieving the body-cavity from the weight which might otherwise rest upon it.

Mr. L. L. Mowbray further directed my attention towards the sand- or mud-digging habits of the fishes in question. After watching the fishes for some time in the tanks of the New York Aquarium the author has repeatedly had occasion to observe a number of specimens in the act of burying. The fishes generally bring themselves into a slightly inclined position, head downwards with the chin close to the bottom, then with a very short dart forwards they "squirm" themselves into the sand. They may also very often be observed wriggling down, without any forward movement, after having been resting for some time on spread postclavicles on top of the sand.

The "squirming" is to be understood as a very rapid, nearly spasmodic oscillating or similar intermittent movement, transversally to the longitudinal axis of the fish. The effectiveness of the 
action is dependant upon the plough-like shape of head and trunk, the flanks being medio-dorsally to latero-ventrally inclined and the belly flattened by the extension of the postclavicles, thus producing a trapezoid transverse outline of the trunk. The squirming of a comparatively heavy, plough-shaped body like this, resting on the bottom, will excavate the sand away from underneath and shovel it up over the flanks, thus digging the fish down and covering it in the same operation. The burrowing starts with a wagging of the head, which more or less imbeds it in the sand. As soon as the head has attained a purchase on the bottom, the activity passes backwards to the postclavicular region, with which we are here concerned. In all the cases observed the squirming in this region appeared to be of a much more violent nature than the preceding wagging of the head, i.e. it had a considerably greater frequency, and from the results produced it seemed to be the main operation in the entire process of burrowing. The initial imbedding of the head may be regarded as probably a preparatory process, fixing the position of the fish before the squirming in the postclavicular region is started and thereby greatly increasing the efficiency of this activity.

The activity in the said region consists in a lifting of the rigidly extended postclavicles alternatingly on the two sides in extremely rapid succession. The lifting seems to be accompanied by an upward twist of the lateral surface of the postclavicles, as should be expected by a contraction of the levator postclavicularis m. obl. inf. (see p. 257), and may thus be regarded as a very efficient shoveling operation. It is very difficult to discern whether the postclavicles in their unlifted state are also more or less retracted and actively depressed. It seems at least as if they are not nearly as rigidly extended as when they are lifted, but they do not on the other hand seem to be gathered close to the sides as by contraction of the pars coraco-analis $m$. recti. The entire operation under discussion may thus either be described as an extending, twisting and lifting or merely as a twisting and lifting of the, in the latter case already rigidly extended, postclavicles on the two sides alternatingly. In any case the squirming will probably be mainly due to the contractions of the levator postclavicularis $\mathrm{m}$. obl. inf. together with tension or contraction of the extensor postclavicularis m. obl. inf. Whether the depression and the retraction, if any, follows actively 
or merely passively upon the relaxation of the above mentioned muscles can not be ascertained.

As already mentioned several times the squirming is very rapid, mainly affecting the flanks and the ventral surface of the fish, the back apparently being essentially quiet but for a quivering unavoidably transmitted to it from the violent motion. The burying operation is often aided by some strokes of the tail and is completed in a few seconds, ten to twenty squirms being performed during this short time. A path to the mouth and from the gill openings is made afterwards by blowing. ${ }^{6}$

Mr. L. L. Mowbray also states in addition to this squirming to have seen the fishes shoveling themselves more quietly and gradually into the bottom. The author has not had opportunity to observe this operation but it may safely be supposed that essentially the same mechanism is employed. It is however probable that by quiet shoveling both sides will be lifted simultaneously and not alternatingly, as the effect would otherwise by slow action merely be a rolling of the fish and not a shoveling of the ground.

It is of interest in connection with the described methods of burying into the ground to remember again that these fishes have no ventral fins to aid their digging.

We thus have found that the postclavicular apparatus of Spheroides maculatus serves the fishes for support when they are resting upon the bottom, for preventing pressure upon the bodycavity and for shoveling when the fishes are burying themselves into the ground. Which function is the main or most important one is difficult to make out, in aquaria there are generally more specimens resting on spread postclavicles on top of the sand than there are buried into it.

It finally should be mentioned that in spite of numerous observations on the swelling of live specimens the author has never been able to observe any actions supporting the theory advanced by Thilo (1899), that the very large postclavicles of the Tetrodontidae through their spreading should serve to enlarge the capacity of the body-cavity, this act being among the main factors of the pumping activity producing the inflation of these fishes. The postclavicular apparatus on the contrary seems quite passive during the swelling,

${ }^{6}$ Unlike most fishes Spheroides and, in fact, nearly all Plectognaths have a well developed faculty for reversing the respiratory current, ejecting jets of water through the mouth. 
and the flattening of the belly, produced by extension of the postclavicles in an uninflated fish, would indeed not occur if the cubic content of the body cavity was increased proportionately with the extension.

\section{The Postclavicular Apparatus of Chilomycterus SCHOEPFII}

In Chilomycterus schoepfi (Walbaum) the author has not been able to discover any independent functions performed by the postclavicular apparatus. It nevertheless appeared that also in this species there is a very peculiar arrangement of musculature connected with the postclavicular bone. The very fact that the features of this muscular arrangement seem to be functionally "inexplicable," greatly enhances the interest attached to them from a phylogenetic and systematic point of view. The main object of the following treatise therefore is a comparative description of the purely morphological details of the postclavicular apparatus in Chilomycterus schoepfii.

\section{Osteological Apparatus}

The greatest osteological differences between the pectoral arches of Chilomycterus and Spheroides are exhibited by the very bones with which we are here mainly concerned viz.: the postclavicles. Except for these bones the pectoral structures are essentially the same in the two species compared, as will appear from a comparison of the Figs. 287 and 291.

The skeletal postclavicular apparatus in Chilomycterus is reduced to a single rather small bone, not in any way articulating with the cleithrum, being on the contrary rather firmly attached to the upper mesial surface of the latter bone through strongly developed connective tissue. The said postclavicular bone of Chilomycterus may be considered as consisting of two rather different parts, a fact probably indicating that the bone has originated through complete fusion of the two bones normally present. However, no traces of a dividing boundary line are now to be found. The anterior part of the postclavicular bone is strong and rod-like, running steeply inclined along the upper mesial surface of the cleithrum, to which it is attached by connective tissue. The posterior part is free from the cleithrum, compressed, high (broad) and thin, with nearly hori- 
zontal upper and lower margins (Fig. 291). The posterior part joins the lower half of the anterior part at an angle of about $120^{\circ}$.

The connection of the pectoral girdle with the skull is of the same type as in Spheroides. The ridges and crests of the cleithrum are very strongly developed. Instead of a ventral lamina on the coracoid there is in Chilomycterus a crest on the mesial surface of this bone running obliquely antero-ventralwards on its lower part. This crest is at its postero-dorsal end produced into a spine-like-process corresponding to the posterior process of the ventral lamina on the coracoid in Spheroides The lower pterygial carries from the middle of its inferior margin a well developed, obliquely mesio-dorsalwards directed tapering process, corresponding to the similar but rather inconspicuous process sometimes found in Spheroides as a prolongation of the small ventral lamina of the lower pterygial in the latter.

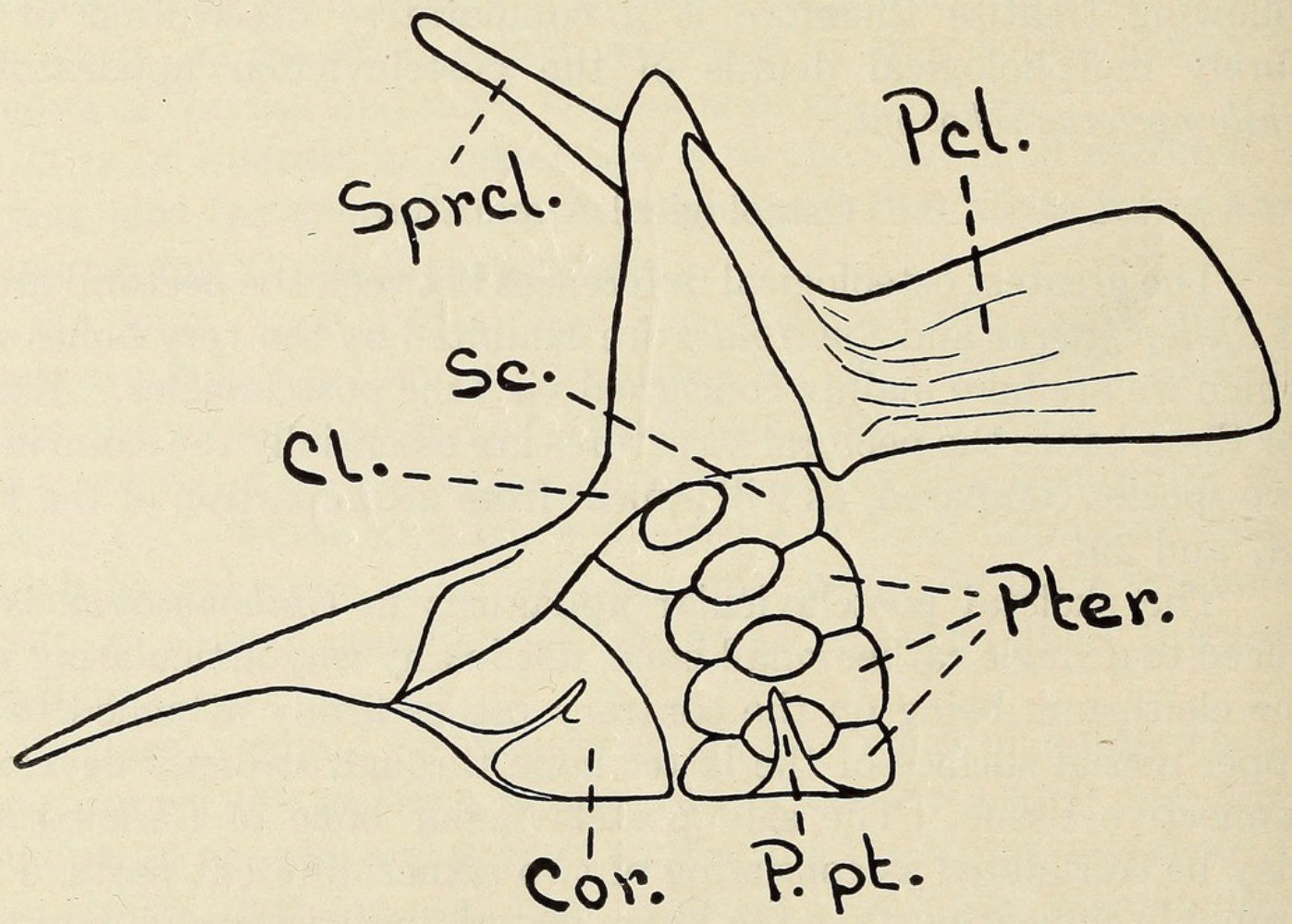

Fig. 291. Mesial view of the right pectoral arch and postclavicular bone of Chilomycterus schoepfi; $\mathrm{Cl}$, cleithrum; Cor, coracoid; $\mathrm{P} . \mathrm{pt}$, process from the ventral margin of the lower pterygial (see text); Pter, pterygials; Sc, scapula; Sprcl, supraclavicular bone.

\section{Myological Apparatus}

In Chilomycterus the ventral skeleto-muscular body-wall is still farther reduced than in Spheroides, being in the former altogether extremely vestigeal. 
The very thin bundle of muscle fibres inserted into the mesial ventral margin of the cleithrum evidently represents what is left of the anterior part of the pars coraco-analis musculi recti. This vestigeal muscle dissolves itself below the postclavicular bone and partly disappears, three strands of fibres may however be traced with interruptions till they also disappear in the lower bundles of the adductores postclavicularis system.

The just mentioned system of musculature is a most peculiar feature of the myology of Chilomycterus. It consists of a varying number of fibre-bundles radiating from the postclavicle towards the dorsal, caudal and posterior ventral parts of the fish as will appear from the fig. 292. The bundles are inserted along the dorsal and posterior margin of the postclavicular bone and into its lower posterior corner. The numbers of the bundles may vary even on the two sides of the same specimen, they are however mostly rather well separated from each other, but this separation may in many cases be of a quite occasional nature. At their peripheral ends the bundles are attached to the connective tissue sheaths of the lateral musculature. Apparently the most powerful part of the bundles attach themselves below the base of the dorsal fin (without any connection with the latter however). Anteriorly the bundles are attached along the back of the fish, posteriorly on the sides of the tail and above the base of the anal fin. It is evident that this entire muscle-system has been derived from the musculus obliquus inferior in the broader sense of the term (including also the m. rectus), it is further probable that the system is mainly homologous with the levator postclavicularis musculi obliqui inferioris spheroidi, how far however it may also be partly homologized with the posterior part of the pars coraco-analis and with the retractor postclavicularis musculi recti spheroidi may on the other hand not be ascertained. The author therefore proposes that the entire system be called the adductores postclavicularis musculi obliqui inferioris chilomycteri, as a contraction of the bundles evidently will serve to pull the postclavicular bone towards the median of the fish. Though the adductores are covering a relatively very great area of the body, their system is still altogether rather weak as they are all very thin.

Opposed to the adductores only one very small muscle is found, running from the process of the crest on the coracoid obliquely dorsalwards, to be inserted into the posterior ventral corner of the 


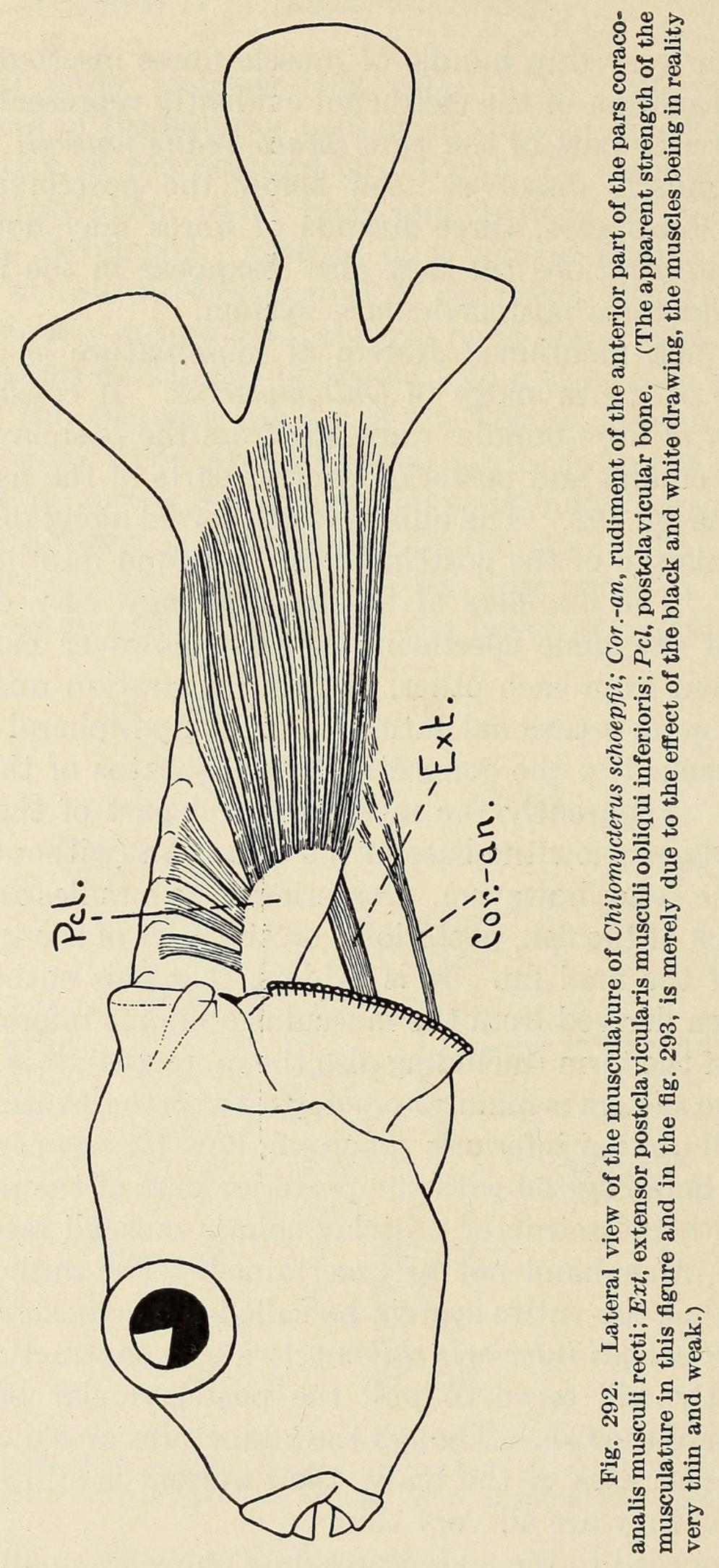


postclavicular bone on its mesial surface (Fig. 293). This muscle evidently is homologous with the extensor postclavicularis musculi obliqui inferioris spheroidi, as the anterior insertion of the former is in details identical with that of the latter, and the difference contributed by the fact that the posterior insertion of the muscle is in Chilomycterus on the mesial not on the lateral surface of the postclavicle, as in Spheroides, may easily be accounted for by the different relative positions of the bones in the species compared, the postclavicular bone of Chilomycterus being in normal state so attached and directed that it is exterior to the crest on the coracoid. We thus have here the extensor postclavicularis musculi obliqui inferioris chilomycteri.

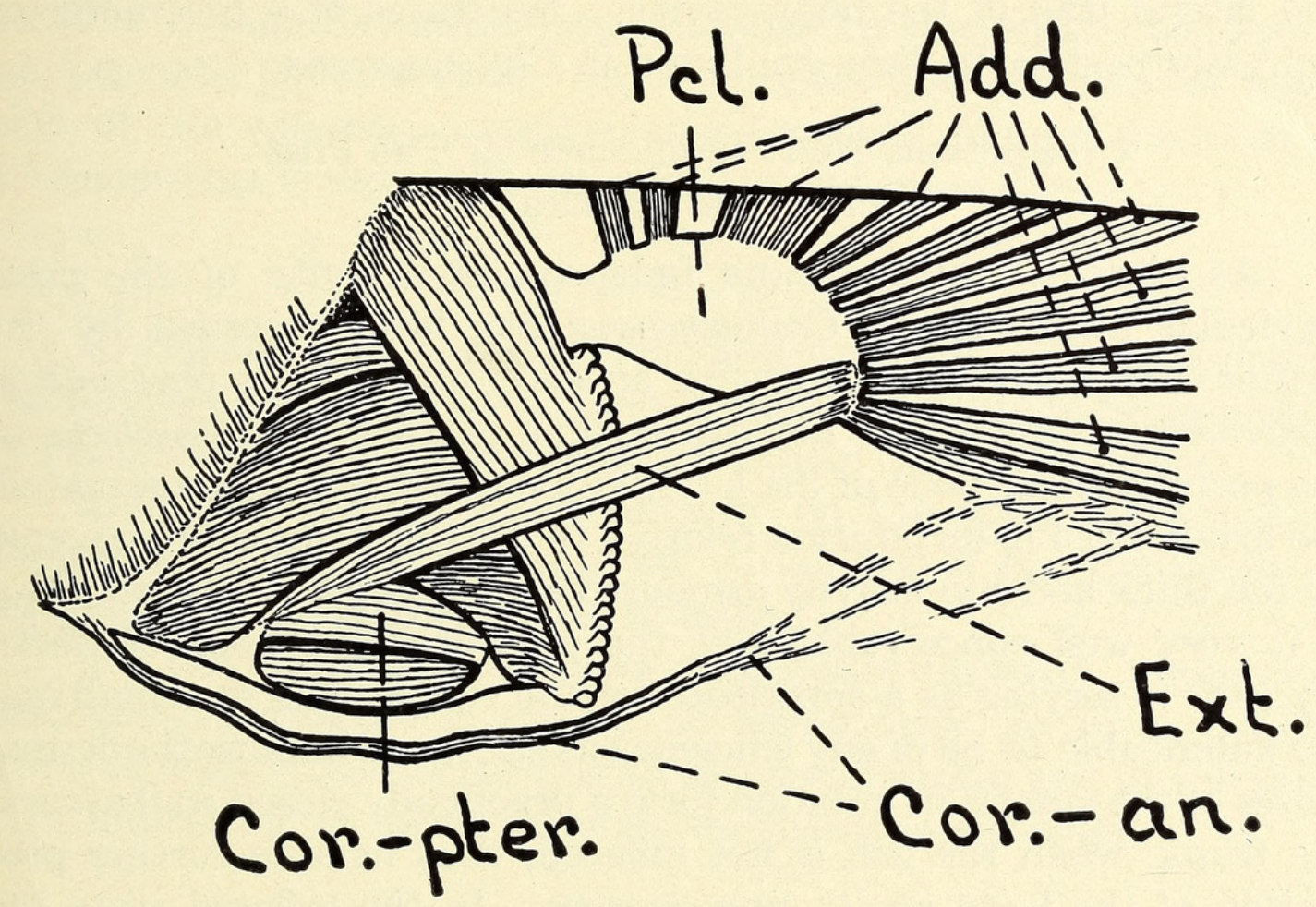

Fig. 293. Interior view of the musculature in the wall of the body-cavity of Chilomycterus schoepfii; Add, adductores postclavicularis musculi obliqui inferioris; Cor.-an, rest of the pars coraco-analis musculi recti; Cor.-pter, pars coraco-pterygialis musculi obliqui inferioris; Ext, extensor postclavicularis musculi obliqui inferioris; Pcl. postclavicular bone. (See also the explanation of fig. 290).

In Chilomycterus we also find another very peculiar muscle connected with the pectoral girdle. This is the pars coraco-pterygialis musculi obliqui inferioris which starts from the postero-dorsal process of the crest on the coracoid together with the extensor postclavicularis, then branches off from the latter and posteriorly inserts itself 
into the process from the inferior margin of the lower pterygial (Fig. 293). Considering its close relation with the extensor postclavicularis in Chilomycterus itself, together with the fact that the anterior insertion of the much more powerful extensor postclavicularis in Spheroides also embraces the small ventral lamina of the lower pterygial and occasionally also a process from the same, we may safely assume that the pars coraco-pterygialis $\mathrm{m}$. obl. inf. is also phylogenetically to be regarded as branched off from the extensor postclavicularis. Functionally the pars coraco-pterygialis m. obl. inf. is perhaps even still more puzzling than any other of the peculiar myological features of Chilomycterus.

The muscles above described are all that is left of the ventral and lateral wall of the body-cavity. No traces of a protractor or depressor postclavicularis are found in Chilomycterus.

\section{Functions And Significance Of The Post- clavicular Apparatus}

As already mentioned no independent activity of the postclavicular apparatus in Chilomycterus has been observed by the author. Separate functions with an external effect as observed in Spheroides are moreover not conceivable at all in Chilomycterus as the postclavicular bone of the latter is too small, too highly situated, too firmly fixed in its position relative to the cleithrum and is covered by too thick and too heavily armoured skin for such purposes. Nor is it very well conceivable that the postclavicular bone of Chilomycterus is serving as a substitute for the ribs as it is too small and too immovable to be of any efficiency as such, and because the dermal plates of the species in question form a practically closed wall around the trunk, when the fish is not inflated, thus making further protection of the body-cavity unnecessary. In the inflated state the protection will in any case be transferred to the skin and the dermal armature. The only significance the postclavicular bone may have thus seems to be as a support and basis of insertion for the muscles attached to it. As for the functions of these muscles it has been quite impossible to show in living specimens that they serve any definite purposes at all. Those of the adductores postclavicularis m. obl. inf. which are horizontal and run caudad might be supposed to partake of the horizontal flexures of the tail. The flexures actually observed however evidently take place behind the posterior 
ends of the adductores. The effect of the very weak adductores compared with that of the much more powerful lateral muscles of the tail would moreover in any case be so small as to render the existence of the former still more puzzling if the function of bending the tail were the only explanation of their presence. Such theory would also leave the anterior more or less transverse adductores quite unexplained. The rather unbalanced proportion between the adductores and their antagonistic muscle the extensor is also peculiar and does not indicate a very active nature of the entire system. The conclusion seems inevitable that the peculiar arrangement of muscles attached to the postclavicular bone in Chilomycterus is functionally inexplicable, ${ }^{7}$ if the functions of an organ, may ever serve to explain its morphology, and may only be understood from a phylogenetic point of view. In this respect the very detailed retention of the extensor postclavicularis musculi obliqui inferioris in Chilomycterus is especially conspicuous and interesting.

\section{SummaRY AND CONCLUSIONS}

A reliable phylogenetic homologizing and a corresponding terminology can not be carried out in sufficient detail to be applicable to many functionally important, specialised muscles in fishes.

A purely descriptive terminology on the other hand is very confusing on account of the great variability of functions and insertions of homologous muscles in fishes.

For the above reasons there is proposed herewith a combined descriptive-phylogenetic system of terminology giving a definite name to each muscle according to its specialisation and at the same time indicating, as far as possible, its phylogenetic origin.

In the Tetrodontidae and the Diodontidae the muscular walls of the body-cavity are more or less degenerate, leaving an open intermuscular space ventrally, where the cavity is only protected by skin and dermal musculature.

In Spheroides there is still a rather powerful part of a rectus left viz.: the pars coraco-analis musculi recti, running from the coracoid to the first pterygiophore of the anal fin.

7 The fact that the lateral musculature of the back is considerably reduced above the entire length of the body-cavity seems to have no relation to the adductores postclavicularis as the latter are far too weak to be able, with their insertions, to influence the flexures of the back to any extent worth mentioning. 
In Chilomycterus the muscular body-walls are still more degenerated than in Spheroides. There is in the former only a very vestigeal anterior part of the pars coraco-analis musculi recti left.

In both Spheroides and Chilomycterus the musculus obliquus inferior is differentiated into a varying set of individual muscles connected with the postclavicular apparatus.

In Spheroides there are two postclavicular bones. The inferior one is compressed and high, and is peculiar in that it is firmly and immovably attached to the superior postclavicle, which in turn forms a sliding articulation with the cleithrum.

The musculature operating the postclavicular apparatus of Spheroides consists of a set of four muscles viz.: the levator, depressor, protractor and extensor postclavicularis which are directly differentiated from the musculus obliquus inferior, in addition to a retractor postclavicularis which has been developed from the rectus.

The features described enables Spheroides to perform locomotor operations with the postclavicular apparatus in the form of burrowing quite independent of activities of other locomotive organs. This, to the best of the author's knowledge is the only case where separate and independent locomotor functions of the postclavicles have ever been observed.

The postclavicular apparatus in Spheroides also serves for support for the body, when the fish is resting upon the bottom, and replaces the ribs as a protection of the body-cavity.

The postclavicular apparatus takes no part in the pumping activities whereby the inflation of Spheroides is produced.

In Chilomycterus there is only one single postclavicular bone, probably developed through complete fusion of the ordinary two. The postclavicular bone does not articulate with the cleithrum but is firmly attached to the latter by connective tissue.

In Chilomycterus the part of the musculus obliquus anterior and inferior to the postclavicular bone has degenerated to a single small muscle homologous with the extensor postclavicularis in Spheroides and is similarly inserted. There is no depressor or protractor postclavicularis. Dorsally and posteriorly there is a peculiar system of muscles radiating from the margins of the postclavicular bone. These muscles are for the greatest part homologous with the levator postclavicularis m. obl. inf. in Spheroides, but may also include the retractor and more or less of the posterior part of the pars coraco- 
analis musculi recti; they are therefore simply named the adductores postclavicularis musculi obliqui inferioris. There is no specially developed retractor postclavicularis.

In Chilomycterus there is also a small very peculiar muscle connecting the coracoid with the lower pterygial.

In Chilomycterus no functions whatever of the postclavicular apparatus have been observed, nor do independent functions of the apparatus in this species seem conceivable. The features of the postclavicular apparatus in Chilomycterus are therefore only explainable from a phylogenetic point of view.

In perfect concordance with the other characters of Spheroides and Chilomycterus a comparison between the myological features of their postclavicular apparatus also reveals Chilomycterus as the more specialised of the two.

The present case illustrates how the myology of fishes may, sometimes even within narrow systematic limits, contribute valuable characters for comparison in addition to the more generally considered osteological features.

Allis, E. P.

\section{BIBLIOGRAPHY}

1903. The Skull and the Cranial and First Spinal Muscles and Nerves in Scomber Scomber. Journal of Morphology. Vol. 18.

Greene, Ch. W. AND C. H.

1913. The Skeletal Musculature of the King Salmon. Bulletin of the U. S. Bureau of Fisheries. Vol. 33.

MAURER, F.

1912. Die ventrale Rumpfmuskulatur der Fische. Jena. Zeitschr. f. Naturwiss. Bd. 49.

ROSEN.

1913. Studies on the Plectognaths. 4. The Body Muscles. Ark. f. Zool. Stockholm. Vol. 8 .

THILO.

1899. Die Entstehung der Luftsacke bei den Kugelfischen. Anat. Anz. Vol. 16. 


\section{$2 \mathrm{BHL}$ Biodiversity Heritage Library}

Parr, Albert Eide. 1927. "On the functions and morphology of the postclavicular apparatus in Spheroides and Chilomycterus." Zoologica: scientific contributions of the New York Zoological Society 9(5), 245-269. https://doi.org/10.5962/p.203745.

View This Item Online: https://www.biodiversitylibrary.org/item/208079

DOI: https://doi.org/10.5962/p.203745

Permalink: https://www.biodiversitylibrary.org/partpdf/203745

\section{Holding Institution}

Smithsonian Libraries

\section{Sponsored by}

Biodiversity Heritage Library

\section{Copyright \& Reuse}

Copyright Status: In Copyright. Digitized with the permission of the rights holder

Rights Holder: Wildlife Conservation Society

License: http://creativecommons.org/licenses/by-nc/3.0/

Rights: https://www.biodiversitylibrary.org/permissions/

This document was created from content at the Biodiversity Heritage Library, the world's largest open access digital library for biodiversity literature and archives. Visit BHL at https://www.biodiversitylibrary.org. 